\title{
Should businesses give a DAM?
}

\begin{abstract}
George Lamptey
is a consultant with over 12 years experience in software development, enterprise content management, enterprise portals and digital asset management. He started his career in professional services in the media division with Sybase before moving to Yahoo! Enterprise Solutions. He then moved into digital asset management for brand communications company Schawk. He focuses on digital media solutions and has experience in digital asset management across a range of industries including packaging, advertising and music.
\end{abstract}

Keywords: enterprise content management, DAM strategy, packaging, music, SOA

Abstract The importance of DAM in organizations where rich media and graphics are traditionally part of the core business has resulted in DAM being a must-have solution within the company. Organizations whose primary business is not centered around rich media are now, however, embarking on initiatives to create and manage digital media with the benefits of DAM becoming more widespread. This paper addresses a number of important points businesses should consider in DAM;

(i) What does DAM bring to an organization and why embark on this initiative.

(ii) The components that make up a DAM solution and how to approach implementation.

(iii) Where does enterprise content management fit into the equation.

(iv) Development of best practices within the industry and knowledge sharing.

(v) Uniqueness of DAM in industry and project and common themes.

(vi) The importance of correct business process when deploying a DAM system.

(vii) Current trends and the future of DAM.

There are a number of benefits that can be gained from DAM within a company, from improved business processes to having a digital archive that is live and useful for asset reuse and exploitation and also for compliance.

Journal of Digital Asset Management (2007) 3, 145-149. doi:10.1057/palgrave.dam.3650076

\section{INTRODUCTION}

A look at the trends, challenges and future of DAM. Despite the fast growth of the enterprise content management (ECM) market, an important component of this area, DAM, is widely misunderstood. Rather than pushing itself to the forefront of the management of images, audio and visual content, it has to date maintained its position either as a small part of ECM or as a growing but quite separate niche. Due to digital media playing an ever-increasing role across a range of industries and not just traditional media companies, this is however set to change.

Gone are the days of just managing lowresolution management. Today, DAM can include a range of image, audio and video formats with services ranging from storage, metadata classification, workflow, distribution and archiving of this content.
Unlike much of ECM or document management that is focused on the creation, access, management, storage and retrieval of text-based documents, a DAM solution cannot be satisfied by any one product off the shelf nor can it be developed in isolation of other business solutions. When considering DAM, businesses need to look at three key areas: strategy, solution and service.

\section{STRATEGY: EMBRACING ALL CONTENT MANAGEMENT NEEDS}

A content strategy needs to cover the whole organization embracing both ECM and DAM. This should also include web content management. Rather than approach one area as if it is disparate from the other, businesses need to understand that the only way for content solutions to add business value is through an 
increased appreciation of how all content in a company is interlinked.

A critical assessment of how a company is going to manage documents and online repositories overall and not just digital content can be advantageous to giving completeness to a DAM solution. Too often once rich media becomes part of the equation, it is tackled without consideration of metadata repositories that hold essential information and services.

\section{SOLUTION: DELIVERING SUCCESSFUL DAM}

Some vendors claim to have the best out-ofthe-box solution for document management and DAM. Businesses should approach implementation by taking the best of breed in different areas and utilizing existing systems, vendors and various components. The reality is that ECM suppliers have a history of standardization in various functions in a document management solution, but rich media content must also be considered and its importance should not be undervalued.

The management of digital assets should not only be the norm for traditional media companies in broadcast, music and advertising whose core assets are rich media content, but also play a critical role in a wide spectrum of companies that recognize the value in creating, exploiting and archiving audio-visual material.

\section{SERVICE: USING THE KNOWLEDGE BASE}

In an industry that is still considered to be a niche market, DAM requires specialists and people who are dedicated and focused in this area. Although it is younger than ECM or document management, the industry is producing competent consultants who can add significant value to strategy and projects.

The DAM Symposium is just one body fostering best practice and encouraging the sharing of experiences between experts within DAM by holding conferences and seminars around the world throughout the year. Ongoing development using expert resources is key, and should be factored in for DAM initiatives. From strategists, architects, business analysts and librarians, these resources should be part of projects in implementation and post implementation (Figure 1).

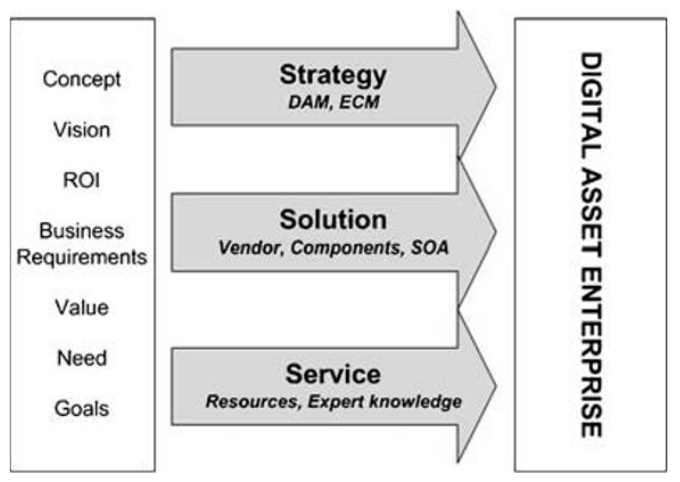

Figure 1: Key-area businesses need to consider in a digital asset enterprise

\section{CHALLENGES}

ECM vs DAM. There needs to be a holistic approach to reap the full benefits of both ECM and DAM as described in the strategy section above. In the current landscape, there are two different directions a business can take if looking from a purely supplier perspective. With this approach and looking at a supplier who has a main offering in DAM, businesses need to assess organizational priorities and understand the potential growth of digital assets in a company. The same can be said where a company is planning for a large increase in text-based documents in the company. In the current landscape, there has been convergence in the supplier market for DAM and ECM, with some suppliers offering solutions for both. The real challenge is in how a business defines its priorities in managing content and realizing that the market is still in the process of consolidation, even within suppliers who have acquired best of breed DAM companies and brought them into their portfolio of ECM components.

\section{BUYER APPROACH}

Despite vendors claiming to offer the best solution in this market, it pays to do the necessary research, always keeping in mind that probably no one vendor will be able to solve all your requirements. It will require expert systems in different areas, and compatibility and integration are key to getting the desired solution. A component approach to a solution involves bringing best of breed together in different areas and also having the scope to explore different avenues, evaluate and use 
existing systems where possible. It can be an invaluable experience to look at several alternatives even during an implementation.

\section{UNIQUENESS OF INDUSTRY AND PROJECT}

Despite the common threads that run through DAM projects such as content creation, defining metadata, workflow and storage, different industries will approach DAM in very different ways. Following are three examples:

\section{Packaging}

In packaging, DAM and workflow systems focus on the production and distribution of artwork. Assets are usually created in native formats such as Quark or InDesign and converted to PDF files that go through a workflow. Workflows within packaging can be extremely complex with many iterations. The regulatory aspects of consumer products are particularly important considerations, especially in foodstuffs and pharmaceuticals.

In packaging, DAM lends itself to make it more efficient and less expensive to manage the production workflow, reducing time to market. Product marketing managers are responsible for managing and producing the required product material necessary for a particular product or product group. The process starts with a product marketing brief. The first step in the workflow is having a brief that can be managed and distributed in a digital workflow to all required participants. Below is a simplified view of few of the core steps that would be in a packaging workflow, the participants and finally the storage of the asset in a DAM system that has gone through the workflow (Figure 2).

Storage and asset reuse is a key driver in having a DAM solution. The entire PDF workflow is digital with all reviews, approvals and annotations online. The asset storage includes metadata association and allows for artwork components to be reused in new product workflows. It can also act as an archive, useful for legal and compliance issues.

\section{Marketing}

In marketing and advertising, campaigns and marketing material need to be developed quickly and frequently. The on-demand aspects in this area are a key differentiator in DAM in this industry. We look at the airline industry. ${ }^{1}$ From billboards at airports to brand materials in airport lounges and brochures, DAM provides benefits. Storage and reuse of photography and products for airlines, for example, are critical for rebranding and launching new marketing campaigns around the world.

A DAM solution for the management of brand components for marketing materials enables dynamic campaign and marketing development using a standardized repository of materials. Core elements of a brand include:

- Logos - the main logo or identifier for the brand.

- Typography - fonts and typefaces used throughout materials and images for the brand.

- Brand guidelines - guidelines on how to work with the brand.

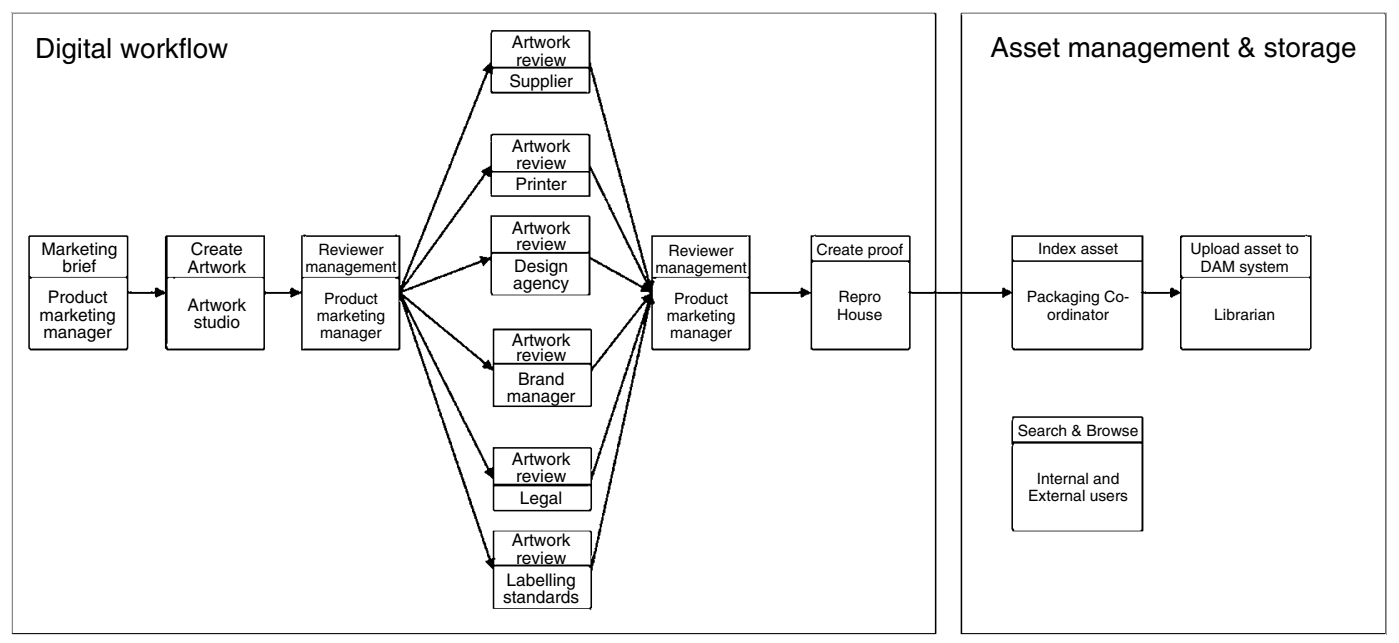

Figure 2: Workflow and asset management 
- Photography - a repository of images and photos created following the brand guidelines.

- Templates - structured online templates for marketing materials.

The elements provide guidance for developers of components for the brand. The DAM solution can store assets that are created using these guidelines that can be distributed to different regions and also stored for asset reuse. The ability to have a DAM solution where you can categorize components of the brand as well as categorize and apply metadata to finished components of marketing material is a key driver for building the business case for a DAM system.

\section{Music}

With the digital revolution taking the music industry by storm, DAM and, more importantly, the management of the digital supply chain is one of the main production challenges that face music companies. With music distribution being dominated by major online retailers, music companies must satisfy the demands of the distributors in terms of formats and standards of audio and audio-visual content. The number of online and mobile distribution channels along with the number of required digital formats is increasing. Other important considerations are the movement of large broadcast quality audio and video files in the process.

In the music process, a complete asset management solution in music consists of having centralized storage and accessibility for digital assets and detailed metadata. The solution should also allow for the creation and exploitation of assets by transforming them into products for the physical and digital supply chains. Metadata will be captured at various levels from basic information such as title, artist and main contributors to more detailed information about product format, territory and exploitation rights. A few definitions

1. Asset - a singular file such as a recording, video or photo.

2. Product - a commercial entity consisting of one or more assets. For example, a CD Single, Digital Album or Wallpaper for a mobile phone.

3. Metadata - information attached to an asset or product. For example, title, artist, producers and rights information.
4. Physical supply chain - Physical products developed for commercial use For example, CD single and DVD.

5. Digital supply chain - Digital products distributed by online and mobile retailers.

We look further at assets and products that are used for promotional and commercial use in the digital supply chain. Products currently fall into the following categories (Figure 3):

(i) audio products such as digital singles (fulltrack downloads) and ringtones;

(ii) audio-visual materials such as video singles, concerts and vodcasts;

(iii) graphics such as wallpapers, games and logos for mobile phones.

Commercial products in digital music have become more complex in addition to singles, albums and ring tones with the addition of graphics and variants in audio and audio-visual content. The market is very dynamic and there is increasing importance in the exploitation of the back catalogs of the major music companies in the digital market. This requires digitization, metadata management and storage of digital assets and content.

The association of metadata for music assets is also needed for management of royalties, sales and digital rights management for example. DAM in music should also be complemented by tools that allow companies to seamlessly manage content from creation to distribution in an efficient manner. This is easier said than done. The proliferation of formats and content creators with different processes and tools adds to the challenges faced in this area along with the distribution of large files through the supply chain.

Some implementations will include all areas listed below, others only a subset. This shows that DAM requirements differ from industry to industry and from project to project. Areas such as document management, rights management and taxonomies are a few additional areas to name a few.

- Asset reuse

- Workflow

- Digital distribution

- Metadata management

- Brand management

- Compliance 


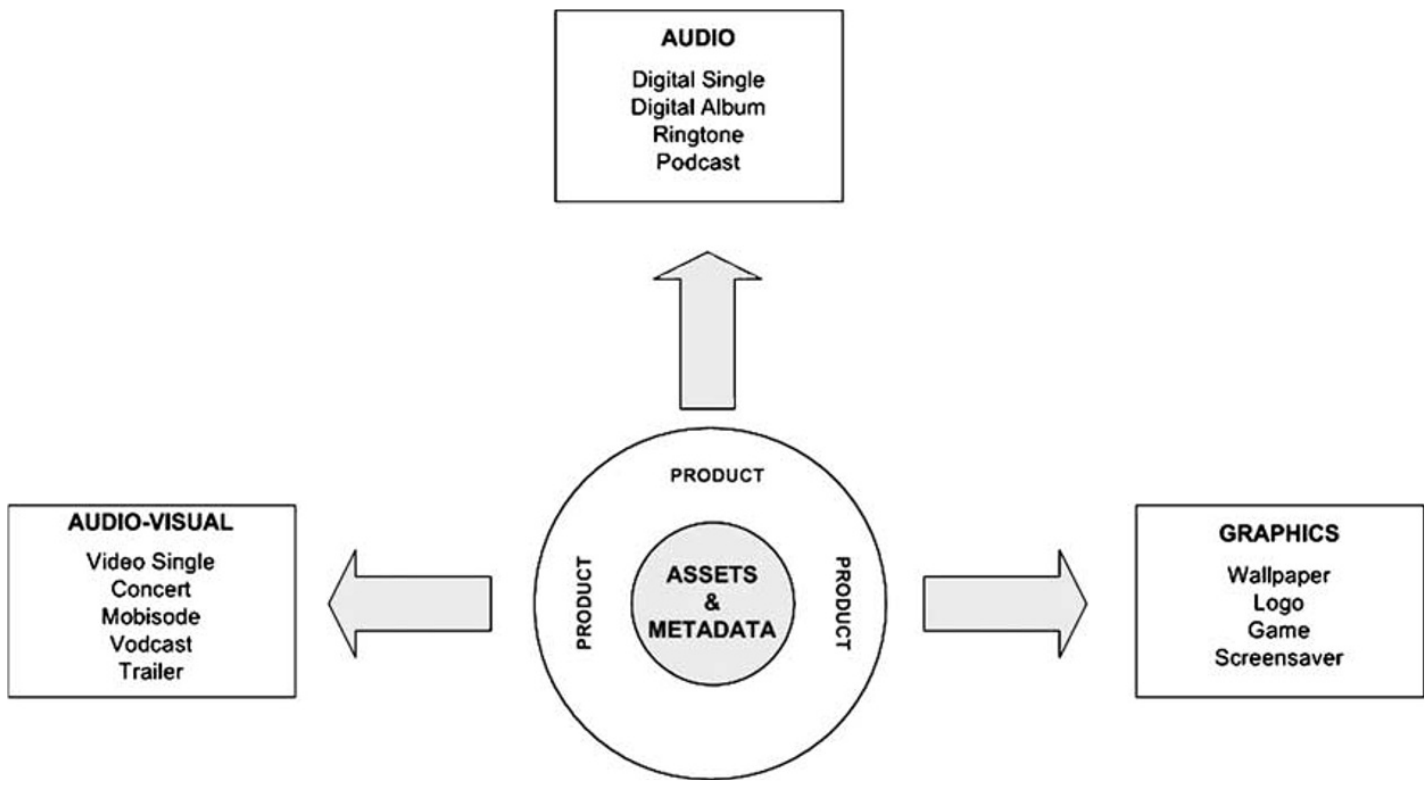

Figure 3: Process of product creation from digital assets and metadata in the digital supply chain

\section{BUSINESS PROCESSES}

Another aspect that should not be ignored is how to marry business processes and DAM. In fact, it should be the total analysis of business processes that leads to the need and business case for DAM. As part of the DAM strategy, businesses should review in detail business processes throughout the organization. The development of Business Process Modeling Notation $(\mathrm{BPMN})^{2}$ will provide businesses with the capability of understanding internal processes in a graphical notation, which may become an industry standard.

\section{LOOKING AHEAD}

As the momentum gathers in the importance of DAM, there is an area in technology that is gaining attention. This is Service-Oriented Architecture (SOA). ${ }^{3}$ Businesses should consider this in DAM. This is good news for the industry but what does SOA add? It describes a software architecture that uses loosely coupled services to support the requirements of business processes and helps to link disparate systems.

Many companies have built bespoke systems to handle information repositories and metadata, which have been extended to hold images, audio and video of relatively small file sizes. These companies can benefit largely from an
SOA approach, which identifies and uses existing systems to get the best out of them.

Prior to SOA, most strategies were formed around implementing a completely new solution and making existing systems redundant. There may be a case for this approach but the maturity of some existing systems and core benefits they have make it useful to have a combination of new and existing services and systems employed.

Businesses that are considering DAM will reap benefits from an approach that is strategic and related to document management in the whole enterprise, a full appreciation of vendors and a full assessment of what components are needed for a solution. They will also benefit from an approach to development where development teams are a continuous part of the project and expert knowledge in DAM is utilized. This is an industry where shared best practices can bring benefits to many projects.

\section{References and Notes}

1 British Airways Brand. http://www.babrand.com.

2 BPMN. http://www.bpmn.org.

3 Service-oriented architecture. http://en.wikipedia. org/wiki/Service_oriented_architecture. 